\title{
Comparison of UV-B Broadband Brewer Measurements with Irradiances from Surface-Based and Satellite-Based Models
}

\author{
Jacqueline Binyamin ${ }^{1}$, John Davies ${ }^{2}$, Bruce McArthur ${ }^{3}$ \\ ${ }^{1}$ Department of Geography, University of Winnipeg, Winnipeg, Canada \\ ${ }^{2}$ School of Geography and Earth Sciences, McMaster University, Hamilton, Canada \\ ${ }^{3}$ Air Quality Research Branch, Meteorological Service of Canada, Toronto, Canada \\ E-mail: j.binyamin@uwinnipeg.ca \\ Received May 1, 2011; revised June 13, 2011; accepted June 28, 2011
}

\begin{abstract}
UV-B irradiance can be estimated from surface meteorological data or from satellite measurements. This paper compares irradiance estimates from the Davies surface-based radiation model and the Canada Centre for Remote Sensing (CCRS) satellite model with Brewer spectrophotometer measurements for all sky conditions at six Canadian stations (Edmonton, Regina, Winnipeg, Montreal, Halifax and Toronto). The Davies model is applied with both the discrete ordinate radiative transfer (DISORT) and the delta-Eddington algorithms to solve the radiative transfer equation.

Both models' estimates are compared with instantaneous Brewer measurements. Both perform similarly with mean bias errors within $6 \%$ of the mean measured irradiance for the measurement period and root mean square errors between $25 \%$ and $30 \%$.
\end{abstract}

Keywords: UV-B Irradiance, Brewer Spectrophotometer, DISORT, Delta-Eddington, TOMS, Satellite-Based Models, Surface-Based Models

\section{Introduction}

Stratospheric ozone depletion increases the amount of harmful UV-B (290 - $325 \mathrm{~nm})$ irradiance reaching the earth's surface [1]. Instruments such as the Brewer spectrophotometer measure spectral irradiance [2], but measurements in Canada and internationally are spatially s-parse and are generally of short duration. Radiation mdels can estimate irradiance for locations and times without measurements and can predict irradiances for possible changes in ozone concentrations.

Radiation models use either surface meteorological data or satellite measurements. Models, which use surface data, apply algorithms, which vary from simple approximations [3] to rigorous solutions of the radiative transfer equation. The two most widely used radiative transfer solutions are the discrete ordinate radiative transfer (DISORT) model [4] and the delta-Eddington model [5]. Since these use local data, they should represent point conditions more accurately than the large area estimates from satellite.
Satellites measure reflected radiances at the top of the atmosphere which, combined with radiative transfer calculations or inversion algorithms, provide estimates of the irradiance at the surface [6-8]. Although satellite measurements provide extensive spatial coverage they usually provide, unless they are sun synchronous, one measurement each day, which prohibits the calculation of daily total irradiance.

Comparisons of model calculations with measurements are mostly restricted to data for a few cloudless days [9-12]. Few studies have validated surface-based models for all sky conditions [13-17].

This paper compares broadband irradiances (290 - 320 $\mathrm{nm})$ from a surface-based model $[16,17]$ and from the Canada Centre for Remote Sensing (CCRS) Meteor-3/ total ozone mapping spectrometer (TOMS) satellite based-model [6-8] with Brewer spectrophotometer measurements in Canada.

\section{Irradiance Measurements}

Brewer spectrophotometer measurements for six Can 
Table 1. Canadian UV-B monitoring stations used in the study.

\begin{tabular}{ccccc}
\hline Station & $\begin{array}{c}\text { Latitude, } \\
{ }^{\circ} \mathrm{N}\end{array}$ & $\begin{array}{c}\text { Longitude, } \\
{ }^{\circ} \mathrm{W}\end{array}$ & $\begin{array}{c}\text { Elevation, } \\
\mathrm{m}\end{array}$ & $\begin{array}{c}\text { Years of } \\
\text { data }\end{array}$ \\
\hline Edmonton (Alta.) & $53^{\circ} 33^{\prime}$ & $114^{\circ} 06^{\prime}$ & 766 & $1993-1994$ \\
Regina (Sask.) & $50^{\circ} 13^{\prime}$ & $104^{\circ} 40^{\prime}$ & 592 & 1994 \\
Winnipeg (Man.) & $49^{\circ} 55^{\prime}$ & $97^{\circ} 14^{\prime}$ & 239 & 1993 \\
Montreal (Que.) & $45^{\circ} 28^{\prime}$ & $73^{\circ} 45^{\prime}$ & 24 & $1993-1994$ \\
Halifax (NS) & $44^{\circ} 44^{\prime}$ & $63^{\circ} 40^{\prime}$ & 31 & $1993-1994$ \\
Toronto (Ont.) & $43^{\circ} 47^{\prime}$ & $79^{\circ} 23^{\prime}$ & 198 & $1993-1994$ \\
\hline
\end{tabular}

dian locations, for which there were simultaneous satellite-based irradiances, are used in this study (Table 1). This instrument allows for the calculation of daily ozone depth and measures spectral irradiance for wavelengths between 290 and $325 \mathrm{~nm}$ at a resolution of $0.5 \mathrm{~nm}$. Radiation measurements are made once or twice each hour from sunrise to sunset at irregular times in GMT [18]. Following Krotkov et al. [12] and Wang et al. [19] the Brewer values were increased by $6 \%$ to compensate for the cosine error.

\section{The Davies Model}

The model developed by Davies et al. [16] and modified by Binyamin et al. [17] is used in this study. Surface irradiance $G$ is calculated as a linear combination of clear $G_{O}$ and overcast $G_{\circledast}$ sky irradiances weighted with cloud fraction $C$ :

$$
G=(1-C) G_{\mathrm{O}}+C G_{\otimes} .
$$

$G_{O}$ and $G_{\otimes}$ are calculated spectrally at wavelength interval of $1 \mathrm{~nm}$ using either the DISORT [4] or the delta-Eddington [5] solutions to the radiative transfer equation for a vertically inhomogeneous 49-layer, 120 $\mathrm{km}$, plane parallel atmosphere, with cloud inserted between 2 and $3 \mathrm{~km}$ heights. The model uses spectral values of the extraterrestrial irradiance from the Solar Ultraviolet Spectral Irradiance Monitor (SUSIM) ATLAS-3 space shuttle mission (D. Prinz, personal communication, 2002), ozone absorption coefficients from Paur and Bass [20], Rayleigh scattering cross sections following Elterman [21], aerosol optical properties from Shettle and Fenn [22], a fixed cloud optical depth of 27 [17,23], and a fixed surface albedo of 0.05 [24]. Hourly total cloud opacity observations were obtained from the Meteorological Service of Canada.

\section{The CCRS Satellite Model}

The CCRS satellite algorithm for retrieving surface irradiance [6] is based on a linear relationship between TOA albedo at $360 \mathrm{~nm}$ and surface absorbed irradiance. The surface irradiance is given by:

$$
G=\frac{S_{0} \cos \theta T_{03}\left(1-0.196-0.798 \alpha_{360}-a_{d}\right)}{\left(1-\alpha_{s}\right)+a_{u} \alpha_{s}}
$$

where $S$ is the extraterrestrial irradiance; $\theta$ the solar zenith angle $; T_{03}$ the band-mean transmittance due to ozone absorption; $\alpha_{360}$ the albedo for the earth-atmosphere system at $360 \mathrm{~nm} ; \alpha_{s}$ surface albedo; and $a_{d}$ and $a_{u}$ represent aerosol absorption for the downwelling and upwelling irradiance.

The extraterrestrial irradiance was taken from Fröhlich and London [25]. Total ozone amount was taken from the TOMS data set. Surface albedo was assumed to be 0.04 for Toronto and 0.03 for other stations. Aerosol optical depth $\tau_{a}$ measurements were available for Toronto [19] and a value of 0.31 was substituted for missing days. For Winnipeg and Edmonton $\tau_{a}$ was assumed to be 0.2 , and 0.1 for the remaining stations. Aerosol single scattering albedo was assumed to be 0.95 for all stations. The model can only be used for days without snow cover.

\section{Comparison of the Davies Model and CCRS Model Results}

The Meteor 3 reflectance measurements were made at different local times, with usually once per day, with a maximum of two values per day that matched the times of Brewer measurements (Pubu Ciren, CCRS, personal communication, 2007). Each CCRS model estimate is compared with a simultaneous Brewer measurement and a calculation from the Davies model using both the delta-Eddington and DISORT methods. There is a small difference in the spectral integration range used by CCRS and the Davies model. CCRS presents irradiances integrated over the $290-320.5 \mathrm{~nm}$ wavebands in $0.5 \mathrm{~nm}$ steps while the Davies irradiances were integrated in 1 $\mathrm{nm}$ steps over the $290-320 \mathrm{~nm}$ range. In this section, both models are compared with Brewer measurements integrated to the upper wavelength limit appropriate to the model.

Comparison of the Davies model broadband irradiances and the simultaneous satellite-based results with Brewer measurements made at six stations (Edmonton, Regina, Winnipeg, Montreal, Halifax and Toronto) in 1993 and 1994 (Table 1) are presented in Figure 1. They represent 10 station years of instantaneous data mainly between May and September, with 605 data points in total. Generally, the agreement between the three is visually good for all stations. The MBE (mean difference) values correspond to less than $0.04 \mathrm{~W} \cdot \mathrm{m}^{-2}$ on average for individual stations and pooled data for both surface-based and satellite-based methods.

Table 2 provides performance statistics for both indi- 



- Edmonton

- Regina

․ Winnipcg

- Montreal

$\triangle$ Halifax

\ Toronto

Figure 1. Comparison between Davies model calculations, CCRS satellite-based model calculations and measured UV- B irradiances for all sky conditions for Edmonton, Regina, Winnipeg, Montreal, Halifax and Toronto. The dotted lines represent linear regressions constrained to pass through the origin. A different symbol represents data for each station.

vidual stations and pooled data. For the pooled data, the Davies model with the delta-Eddington and DISORT methods and the CCRS model underestimate Brewer measurements by less than $6 \%$ of the mean measured irradiance. For the individual stations the relative MBE values range between $\pm 6 \%$ for the delta-Eddington method, between $-10 \%$ and $0.2 \%$ for the DISORT method and between $-11 \%$ and $0.3 \%$ for the satellite-based method. These irradiance differences are smaller than dif- ferences between near simultaneous measurements made with different ground instruments $\pm 10 \%$ [26-29]. The relative RMSE values for the pooled data are similar $(26 \%$ and $29 \%$ ) for the two methods. For the individual stations, relative RMSE values range from 24 to $34 \%$ for the Davies model and from 20 to $40 \%$ for the satellitebased model. This agrees well with the findings of Fioletov et al. [30] and Wang et al. [31] who found that differences between TOMS-estimated UV-B irradiances 
Table 2. Summary of the Davies model and satellite-based method performance measures against Brewer measurements for broadband irradiances $(290-320 \mathrm{~nm})$ for each satellite time for the period indicated for each station. $N$ is the number of data points and $\bar{M}$ is the mean measured irradiance $\left(\mathrm{W} \cdot \mathbf{m}^{-2}\right)$. MBE and RMSE are expressed as percentages (italic) of $\bar{M}$. Positive MBE values indicate model overestimation.

\begin{tabular}{|c|c|c|c|c|c|c|c|}
\hline Irradiance results & $\begin{array}{l}\text { Edmonton } \\
1993-1994\end{array}$ & Regina 1994 & Winnipeg 1993 & $\begin{array}{c}\text { Montreal } \\
1993-1994\end{array}$ & $\begin{array}{c}\text { Halifax } \\
1993-1994\end{array}$ & $\begin{array}{c}\text { Toronto } \\
1993-1994\end{array}$ & Pooled data \\
\hline$N$ & 115 & 48 & 88 & 20 & 159 & 175 & 605 \\
\hline \multicolumn{8}{|c|}{ Davies model using delta-Eddington metho } \\
\hline $\bar{M}$ & 1.16 & 1.20 & 1.54 & 0.66 & 1.19 & 1.13 & 1.21 \\
\hline MBE & 6.22 & -0.79 & -4.97 & 2.13 & -5.66 & 3.64 & -0.29 \\
\hline RMSE & 31.73 & 25.05 & 24.25 & 26.53 & 24.50 & 33.46 & 28.59 \\
\hline \multicolumn{8}{|c|}{ Davies model using DISORT method } \\
\hline RMSE & 28.94 & 25.72 & 25.88 & 27.76 & 25.93 & 33.85 & 28.91 \\
\hline \multicolumn{8}{|c|}{ Satellite method } \\
\hline $\bar{M}$ & 1.26 & 1.31 & 1.68 & 0.72 & 1.30 & 1.23 & 1.31 \\
\hline MBE & 0.26 & -5.14 & -9.75 & -10.86 & -1.40 & 0.06 & -2.73 \\
\hline RMSE & 25.49 & 22.30 & 24.11 & 40.05 & 20.45 & 31.03 & 25.76 \\
\hline
\end{tabular}

and Brewer observations range from 3 to $11 \%$ and can be attributed to the Brewer angular response error.

\section{Conclusions}

This is the first study to compare the performance of satellite-based model with ground-based model estimates of UV-B irradiance. The two models perform almost identically. Differences in performance are within the uncertainties in Brewer measurements. Different fields of view of the TOMS instrument, the Brewer spectrophotometer and the Davies model seem to be inconsequential.

The satellite model can be applied virtually anywhere and does not require other observations. However, it does have two drawbacks. Firstly, because it cannot calculate irradiance throughout the day, it cannot produce daily totals. Secondly, it cannot be used over snow-covered surfaces because it is incapable of discriminating differences between cloud and surface reflections. The Davies model produces daily irradiance totals but its use is currently restricted to stations with cloud observations. Future work should examine the use of satellite cloud data. The use of the delta-Eddington method is especially appealing for calculating broadband irradiances since it is computationally less demanding than DISORT

\section{References}

[1] S. Madronich, "Implication of Recent Total Atmospheric Ozone Measurements for Biologically Active Ultraviolet Radiation Reaching the Earth's Surface," Geophysical Research Letters, Vol. 19, No. 1, 1992, pp. 37-40. doi:10.1029/91GL02954

[2] J. B. Kerr, C. T. McElroy, D. I. Wardle, R. A. Olafson and W. F. J. Evans, "The Automated Brewer Spectrophotometer," In: C. S. Zerefos and A. Ghazi, Eds., Atmospheric Ozone. Proceedings of Quadrennial Ozone Symposium, D. Reidel, Dordrecht, 1985, pp. 396-401.
[3] P. F. Schippnick and A. E. S. Green, "Analytical Characterization of Spectral Actinc Flux and Spectral Irradiance in the Middle Ultraviolet," Phtochemistry and Phtobiology, Vol. 35, No. 1, 1982, pp. 89-101. doi:10.1111/j.1751-1097.1982.tb03815.x

[4] K. Stamnes, S.-C. Tsay, W. J. Wiscombe and K. Jayawerra, "Numerically Stable Algorithm for Discrete Ordinate Method Radiative Transfer in Multiple Scattering and Emitting Layered Media," Applied Optics, Vol. 27, No. 2, 1988, pp. 2503-2509. doi:10.1364/AO.27.002502

[5] J. H. Joseph, W. J. Wiscombe and J. A. Weinman, "The Delta-Eddington Approximation for Radiative Flux Transfer," Journal of the Atmospheric Sciences, Vol. 33, No. 12, 1976, pp. 2452-2459. doi:10.1175/1520-0469(1976)033<2452:TDEAFR $>2.0 . \mathrm{C}$ $\underline{\mathrm{O} ; 2}$

[6] Z. Li, P. Wang and J. Cihlar, "A Simple and Efficient Method for Retrieving Surface UV Radiation Dose Rate from Satellite," Journal of Geophysical Research, Vol. 105, No. 4, 2000, pp. 5027-5036. doi:10.1029/1999JD900124

[7] C. Pubu and Z. Li, "Anisotropic Reflection of UV Radiation at the Top of the Atmosphere: Characteristics and Models Obtained from Meteor 3/TOMS," Journal of Geophysical Research, Vol. 106, No. D5, 2001, pp. 47414755. doi:10.1029/2000JD900440

[8] C. Pubu and Z. Li, "Long-term Global Earth Surface Ultraviolet Radiation Exposure Derived from ISCCP and TOMS Satellite Measurements," Agricultural and Forest Meteorology, Vol. 120, No. 1-4, 2003, pp. 51-68. doi:10.1016/j.agrformet.2003.08.033

[9] J. Zeng, R. McKenzie, K. Stamnes, M. Wineland and J. Rosen, "Measured UV Spectra Compared with Discrete Ordinate Method Simulations," Journal of Geophysical Research, Vol. 99, No. D11, 1994, pp. 23019-23030. doi:10.1029/94JD02145

[10] P. Wang and J. Lenoble, "Comparison between Measurements and Modeling of UV-B Irradiance for Clear Sky: A Case Study," Applied Optics, Vol. 33, No. 18, 1994, pp. 3964-3971. doi:10.1364/AO.33.003964 
[11] B. Mayer, G. Seckmeyer and A. Kyling, "Systematic Long-Term Comparison of Spectral UV Measurements and UVSPEC Modeling Results," Journal of Geophysical Research, Vol. 102, No. 7, 1997, pp. 8755-8767. doi:10.1029/97JD00240

[12] N. A. Krotkov, P. K. Bhartia, J. R. Herman, V. Fioletov and J. Kerr, "Satellite Estimation of Spectral Surface UV Irradiance in the Presence of Tropospheric Aerosols 1. Cloud-Free Case," Journal of Geophysical Research, Vol. 103, No. D8, 1998, pp. 8779-8793. doi:10.1029/98JD00233

[13] E. Leontyeva and K. Stamnes, "Estimations of Cloud Optical Thickness from Ground-Based Measurements of Incoming Solar Radiation in the Arctic," Journal of Climate, Vol. 7, No. 4, 1994, pp. 566-578. doi:10.1175/1520-0442(1994)007<0566:EOCOTF $>2.0$.C $\underline{\mathrm{O} ; 2}$

[14] P. M. de F. Forster, K. P. Shine and A. R. Webb, "Modelling Ultraviolet Radiation at the Earth's Surface. Part II: Model and Instrument Comparison," Journal of Applied Meteorology, Vol. 34, No. 7, 1995, pp. 2426-2439. doi:10.1175/1520-0450(1995)034<2426:MURATE $>2.0$. $\mathrm{CO} ; 2$

[15] D. Lubin and E. H. Jenson, "Effects of Clouds and Stratospheric Ozone Depletion on Ultraviolet Radiation Trends," Nature, Vol. 377, 1995, pp. 710-713. doi:10.1038/377710a0

[16] J. Davies, P. Kuhn, G. Duhamel, J. Binyamin and K. Runnalls, "An Ultraviolet (290 - $325 \mathrm{~nm}$ ) Irradiation Model for Southern Canadian Conditions," Physical Geography, Vol. 21, No. 4, 2000, pp. 327-344.

[17] J. Binyamin, J. Davies and B. McArthur, "Validation of Spectral and Broadband UV-B (290 - $325 \mathrm{~nm})$ Irradiance for Canada," Atmospheric and Climate Sciences, Vol. 1, No. 3, 2011, In press.

[18] J. B. Kerr and C. T. McElory, "Evidence for Large Upward Trends of Ultraviolet-B Radiation Linked to Ozone Depletion," Science, Vol. 262, No. 2136, 1993, pp. 10321035. doi:10.1126/science.262.5136.1032

[19] P. Wang, Z. Li, J. Cihlar, D. I. Wardle and J. Kerr," Validation of an UV Inversion Algorithm Using Satellite and Surface Measurements," Journal of Geophysical Research, Vol. 105, No. D4, 2000, pp. 5037-5048. doi:10.1029/1999JD900403

[20] R. J. Paur and A. M. Bass, "The Ultraviolet Cross-Sections of Ozone: II. Results and Temperature Dependence" In: C. Zerefos and A. Ghaz, Eds., Atmospheric Ozone Proceedings of the Quadrennial Ozone Symposium, D. Reidel, Dordrecht, 1985, pp. 606-616.

[21] L. Elterman, "UV, Visible and IR Attenuation for Altitudes to $50 \mathrm{~km}$," Air Force Cambridge Research Laboratory, No. 285, Cambridge, 1986.
[22] E. P. Shettle and R. W. Fenn, "Models for the Aerosols of the Lower Atmosphere and the Effects of Humidity Variations on Their Optical Properties," Air Force Geophysics Laboratory (AFGL), 1979.

[23] J. Binyamin, J. Davies and B. McArthur, "UV-B Cloud Optical Properties for Canada," International Journal of Climatology, Vol. 30, No. 8, 2010, pp. 1246-1255. doi:10.1002/joc.1966

[24] D. E. Bowker, R. E. Davis, D. I. Myrick, K. Stacy and W. T. Jones, "Spectral Reflectance of Natural Targets for Use in Remote Sensing Studies," NASA reference publication 1139, NASA, Langley Research Center, Hampton, 1985.

[25] C. Fröhlich and J. London, "Revised Instruction Manual on Radiation Instruments and Measurements," WMO Technology Note 149, World Meteorology Organization, Geneva, 1986.

[26] R. L. McKenzie, M. Kotkamp, G. Seckmeyer, R. Erb, C. R. Roy, H. P. Gies and S. T. Toomey, "First Southern Hemisphere Intercomparison of Measured Solar UV Spectra," Geophysical Research Letters, Vol. 20, No. 20, 1993, pp. 2223-2226. doi:10.1029/93GL02359

[27] A. F. Bais, B. G. Gardiner, H. Slaper, M. Blumthaler, G. Bernhard, R. McKenize, A. R. Wedd, G. Seckmeyer, B. Kjeldstad, T. Koskela, P. J. Kirsch, J. Gröbner, J. B. Kerr, S. Kazadzis, K. Leszczynski, D. Wardle, W. Josefsson, C. Brogniez, D. Gillotay, H. Reinen, P. Weihs, T. Svenoe, P. Eriksen, F. Kuik and A. Redondas, "SUSPEN Intercomparison of Ultraviolet Spectroradiometers," Journal of Geophysical Research, Vol. 106, No. D12, 2001, pp. 12509-12525. doi:10.1029/2000JD900561

[28] O. Meinander, S. Kazadzis, M. Blumthaler, L. Ylianttila, B. Johnsen, K. Lakkala, T. Koskela and W. Josefsson, "Diurnal Discrepancies in Spectral Solar UV Radiation Measurements," Applied Optics, Vol. 45, No. 21, 2006, pp. 5346-5357. doi:10.1364/AO.45.005346

[29] S. Kazadzis, A. Bais, A. Arola, N. Krotkov, N. Kouremeti and C. Meleti, "Ozone Monitoring Instrument Spectral UV Irradiance Products: Comparison with Ground Based Measurements at an Urban Environment", Atmospheric Chemistry and Physics, Vol. 9, 2009, pp. 585-594. doi:10.5194/acp-9-585-2009

[30] V. E. Fioletov, J. B. Kerr and D. I. Wardle, "Comparison of Brewer Ultraviolet Irradiance Measurements with Total Ozone Mapping Spectrometer Satellite Retrievals," Optical Engineering, Vol. 41, No. 12, 2002, p. 3051. doi:10.1117/1.1516818

[31] T. J. Wang, K. S. Lam, Q. Liu and T. K. Chan, "Assessment of Long Term UV Radiation Measured by the Brewer Spectrophotometer in Hong Kong during 19952005," Atmospheric and Climate Sciences, Vol. 1, No. 1, 2011, pp. 9-17. doi:10.4236/acs.2011.11002 